\title{
Determinants of myocardial energetics and efficiency in symptomatic hypertrophic cardiomyopathy
}

\author{
Stefan A. J. Timmer • Tjeerd Germans • Marco J. W. Götte • Iris K. Rüssel • \\ Pieter A. Dijkmans • Mark Lubberink • Jurrien M. ten Berg • Folkert J. ten Cate • \\ Adriaan A. Lammertsma • Paul Knaapen • Albert C. van Rossum
}

Received: 7 September 2009 /Accepted: 1 December 2009/Published online: 13 January 2010

(C) Springer-Verlag 2010

\begin{abstract}
Purpose Next to hypertrophy, hypertrophic cardiomyopathy $(\mathrm{HCM})$ is characterized by alterations in myocardial energetics. A small number of studies have shown that myocardial external efficiency (MEE), defined by external work $(\mathrm{EW})$ in relation to myocardial oxidative metabolism $\left(\mathrm{MVO}_{2}\right)$, is reduced. The present study was conducted to identify determinants of MEE in patients with HCM by use of dynamic positron emission tomography (PET) and cardiovascular magnetic resonance imaging (CMR).

Methods Twenty patients with HCM (12 men, mean age: $55.2 \pm 13.9$ years) and 11 healthy controls $(7$ men, mean age: $48.1 \pm 10$ years) were studied with $\left[{ }^{11} \mathrm{C}\right]$ acetate PET to assess $\mathrm{MVO}_{2}$. CMR was performed to determine left ventricular (LV) volumes and mass (LVM). Univariate and multivariate analyses were employed to determine independent predictors of myocardial efficiency.
\end{abstract}

S. A. J. Timmer • T. Germans • M. J. W. Götte I. K. Rüssel

P. A. Dijkmans $\cdot$ P. Knaapen $(\varangle) \cdot$ A. C. van Rossum

Department of Cardiology, 5F, VU University Medical Center,

De Boelelaan 1117,

1081 HV Amsterdam, The Netherlands

e-mail: p.knaapen@vumc.nl

M. Lubberink $\cdot$ A. A. Lammertsma

Department of Nuclear Medicine \& PET Research,

VU University Medical Center,

Amsterdam, The Netherlands

J. M. ten Berg

Department of Cardiology, St. Antonius Hospital,

Nieuwegein, The Netherlands

F. J. ten Cate

Department of Cardiology, Thoraxcenter Erasmus Medical Center,

Rotterdam, The Netherlands
Results Between study groups, $\mathrm{MVO}_{2}$ (controls: $0.12 \pm$ $0.04 \mathrm{ml} \cdot \mathrm{min}^{-1} \cdot \mathrm{g}^{-1}$, HCM: $0.13 \pm 0.05 \mathrm{ml} \cdot \mathrm{min}^{-1} \cdot \mathrm{g}^{-1}, p=$ 0.64 ) and $\mathrm{EW}$ (controls: 9,139 $\pm 2,484 \mathrm{mmHg} \cdot \mathrm{ml}, \mathrm{HCM}$ : $9,368 \pm 2,907 \mathrm{mmHg} \cdot \mathrm{ml}, p=0.83)$ were comparable, whereas LVM was significantly higher (controls: $99 \pm 21 \mathrm{~g}$, HCM: $200 \pm 76 \mathrm{~g}, p<0.001)$ and MEE was decreased in HCM patients (controls: $35 \pm 8 \%$, HCM: $21 \pm 10 \%, p<$ 0.001). MEE was related to stroke volume (SV), LV outflow tract gradient, $\mathrm{NH}_{2}$-terminal pro-brain natriuretic peptide (NT-proBNP) and serum free fatty acid levels (all $p<0.05)$. Multivariate analysis revealed that $\mathrm{SV}(\beta=0.74$, $p<0.001)$ and $\operatorname{LVM}(\beta=-0.43, p=0.013)$ were independently related to MEE.

Conclusion HCM is characterized by unaltered $\mathrm{MVO}_{2}$, impaired EW generation per gram of myocardial tissue and subsequent deteriorated myocardial efficiency. Mechanical external efficiency could independently be predicted by SV and LVM.

Keywords Myocardial efficiency - Oxygen consumption . $[11 \mathrm{C}]$ Acetate $\cdot$ Hypertrophic cardiomyopathy $\cdot$ Imaging

\section{Introduction}

Hypertrophic cardiomyopathy (HCM) is a genetic cardiac disease phenotypically expressed by left ventricular (LV) hypertrophy, which predominantly affects the interventricular septum [1]. In addition, HCM is characterized by alterations in myocardial energy metabolism. Ishiwata et al. demonstrated that cardiac work in relation to oxidative metabolism, i.e. myocardial efficiency, was reduced not only in the hypertrophied septum but also in the lateral wall [2]. Similarly, an impaired energetic status as reflected by the phosphocreatine to adenosine triphosphate ratio, derived 
by ${ }^{31} \mathrm{P}$ spectroscopy, has been documented in different stages of the disease process [3-6]. Although prognostic data related to an impaired energetic state in HCM are lacking, in analogy with other cardiomyopathies, it is believed to be of prognostic relevance $[7,8]$. Insights into the mechanism and causative factors of altered energy metabolism could therefore be of clinical importance in risk stratification and the development and application of (new) therapeutic approaches. Recent advances in imaging techniques offer the possibility to accurately assess myocardial oxygen consumption $\left(\mathrm{MVO}_{2}\right)$, regional mechanical work and tissue characteristics non-invasively using dynamic positron emission tomography (PET) $[9,10]$ and cardiac magnetic resonance imaging (CMR) [11-13], respectively. The present study was conducted to identify the determinants of impaired myocardial energetics and efficiency in patients with symptomatic HCM with the use of these currently available advanced imaging techniques.

\section{Methods}

\section{Subjects}

Twenty patients with non-familial HCM were enrolled in the study. HCM was diagnosed according to the presence of a hypertrophied and non-dilated left ventricle (LV) on twodimensional echocardiography (maximal wall thickness $>15 \mathrm{~mm}$ in adults), in the absence of other systemic or cardiac causes of LV hypertrophy [14]. The pattern of hypertrophy was asymmetrical septal hypertrophy in all patients. Coronary angiography was performed to exclude coronary artery disease $(\mathrm{CAD})$ and myocardial bridging. All patients were using beta blockers or calcium channel blocking agents, which were not discontinued. Eleven healthy adults with normal physical examination, two-dimensional echocardiography and electrocardiogram without a relevant medical history served as controls. The study protocol was approved by the Medical Ethics Committee of the VU University Medical Center, Amsterdam, The Netherlands.

Imaging protocols

\section{PET}

All scans were obtained under resting conditions after overnight fasting, in two-dimensional mode, by use of an ECAT EXACT HR + scanner (Siemens/CTI, Knoxville, TN, USA). A transmission scan was performed using three rod sources filled with ${ }^{68} \mathrm{Ga} /{ }^{68} \mathrm{Ge}$ solution. Subsequently, $550 \mathrm{MBq}$ of $\left[{ }^{11} \mathrm{C}\right]$ acetate was injected and simultaneously a dynamic 29-frame acquisition was performed lasting $48 \min (12 \times 10,3 \times 20,4 \times 60,3 \times 120$ and $7 \times 300 \mathrm{~s})$. During the PET acquisition, venous blood was drawn and $\mathrm{NH}_{2}$ terminal pro-brain natriuretic peptide (NT-proBNP, expressed in $\mathrm{ng} / \mathrm{l}$ ), haemoglobin $(\mathrm{Hb})$, free fatty acids (FFA), glucose and lactate levels were determined. Blood pressure and heart rate were recorded at regular intervals during the PET studies.

\section{$C M R$}

CMR studies were performed on a 1.5-T whole-body scanner (Magnetom Sonata, Siemens, Erlangen, Germany), using a six-channel phased array body coil.

After survey scans, a retro-triggered, balanced steadystate free precession gradient-echo sequence was used for cine imaging. Image parameters were: slice thickness $5 \mathrm{~mm}$, slice gap $5 \mathrm{~mm}$, temporal resolution $<50 \mathrm{~ms}$, repetition time $3.2 \mathrm{~ms}$, echo time $1.54 \mathrm{~ms}$, flip angle $60^{\circ}$ and a typical image resolution of $1.3 * 1.6 \mathrm{~mm}$. The number of phases within the cardiac cycle was set at 20 .

After the four-, three-, and two-chamber view cines were obtained, a stack of six to ten transversely oriented slices was planned on an end-diastolic (ED) two-chamber view at the level of the lower leading edge of the mitral valve annulus to cover the left atrium (LA) [15]. Then, a stack of 10-12 shortaxis slices were acquired for full coverage of the LV used for assessing LV volumes, mass and ejection fraction (see Fig. 1). The method of planning the image acquisition for LV coverage has been described previously [16]. Cine images were acquired during one breath-hold in mild expiration.

Aortic flow measurements were performed with a nonbreath-hold, retrospective, ECG-triggered, phase-contrast velocity mapping sequence with the encoding velocity set at $150 \mathrm{~cm} \cdot \mathrm{s}^{-1}$. The image plane was planned on a coronal view of the thorax, perpendicular to the ascending aorta. Acquisition of the entire cardiac cycle was achieved by setting the acquisition window to $120 \%$ of the cardiac cycle length. To minimize the effects of eddy currents and Maxwell gradients on velocity acquisition, patients were positioned in the isocentre of the scanner.

Cine imaging with myocardial tagging was applied to create non-invasive markers (tags) within the myocardium for calculation of strain [11]. Three short-axis tagged images with complementary spatial modulation of magnetization tagging for improved strain calculations were acquired as previously described [17].

Delayed contrast enhanced (DCE) images were acquired $10-15 \mathrm{~min}$ after intravenous administration of $0.2 \mathrm{mmol} / \mathrm{kg}$ gadolinium, by using a two-dimensional segmented inversion recovery prepared gradient-echo sequence. Inversion recovery time was 250-300 ms. Figure 1 illustrates examples of CMR cine and tagging images during ED and end-systole (ES) as well as a DCE image and phase-contrast velocity map, all representative for the HCM phenotype. 


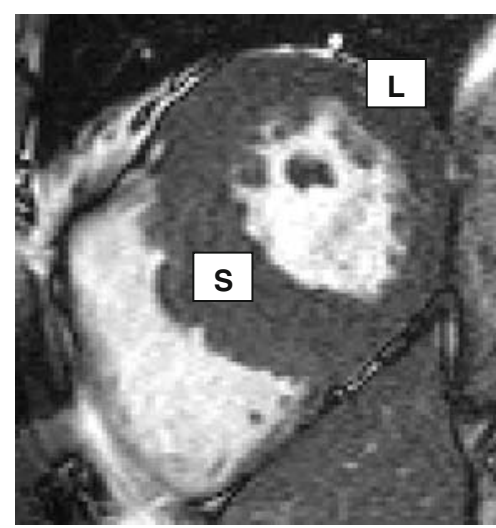

A

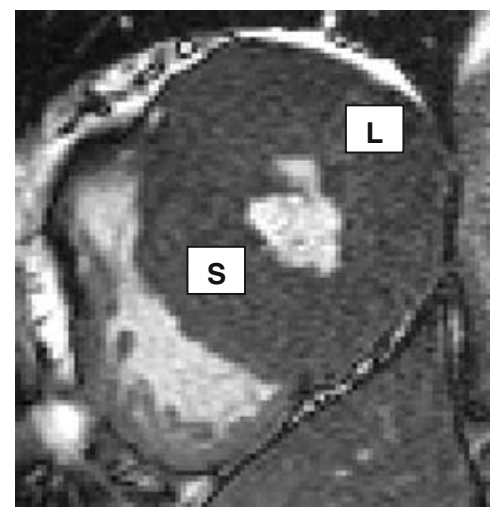

$A^{\prime}$

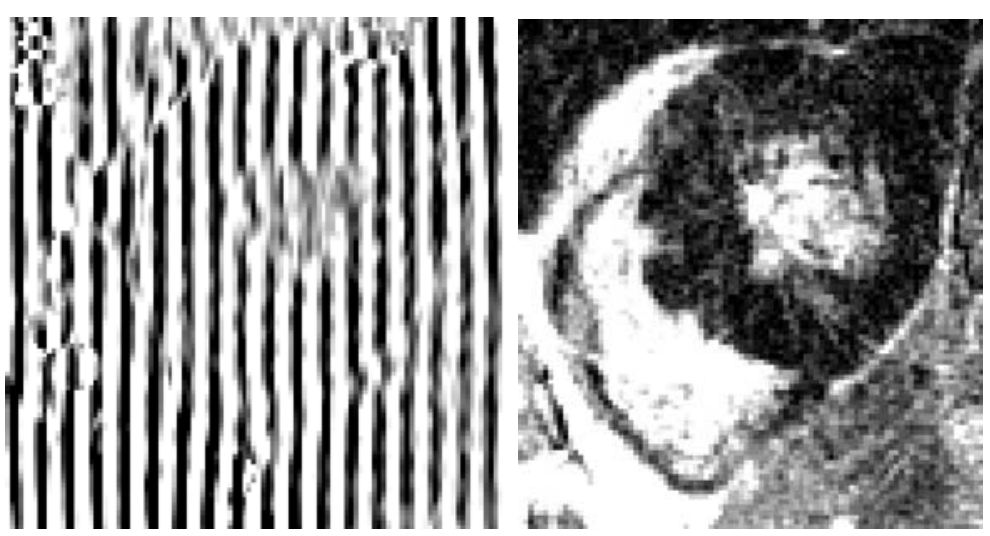

C

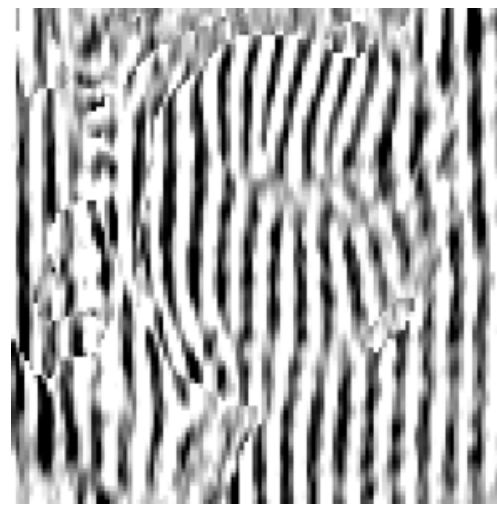

B'

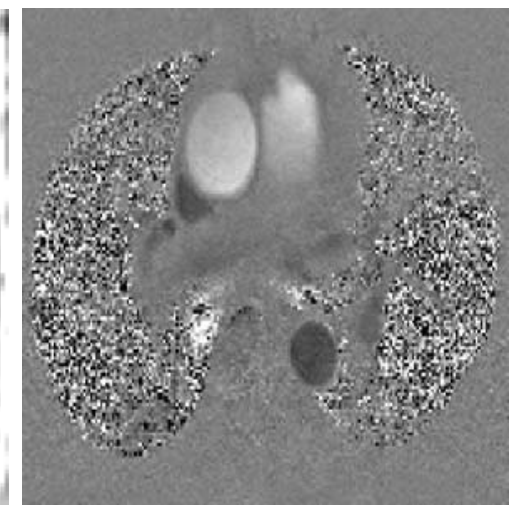

D
Fig. 1 Examples of CMR short-axis cine images at end-diastole (a) and end-systole (a'). CMR short-axis tagging images at end-diastole (b) and end-systole (b') with characteristically decreased septal deformation compared to the lateral wall at end-systole. c CMR

\section{Echocardiography}

Transthoracic two-dimensional echocardiography was performed on a Vivid 7 (General Electrics-Vingmed, Milwaukee, WI, USA). Systolic anterior motion of the mitral valve (SAM) was qualitatively graded, whereas mitral regurgitation (MR) was quantitatively graded on a scale from 0 (no regurgitation) to 4 (severe regurgitation). The pressure gradient across the LV outflow tract (LVOTG) was estimated by use of pulsedwave Doppler.

Data analysis

\section{PET}

Data were transferred to a SUN workstation and analysed using Siemens/CTI software and MATLAB. Regions of interest (ROIs) were defined manually on the maximum intensity $\left[{ }^{11} \mathrm{C}\right]$ acetate short-axis images at the basal, midventricular and apical level of the LV according to a 13-segment model as described previously in detail [18]. short-axis delayed contrast enhancement image with a patchy appearance. d Aortic velocity-encoded phase-contrast flow map. $S$ septum, $L$ lateral wall

This set of ROIs was projected onto the $\left[{ }^{11} \mathrm{C}\right]$ acetate images to generate time-activity curves (TAC). The linear myocardial washout part of the $\left[{ }^{11} \mathrm{C}\right]$ acetate TAC was determined automatically and fitted in a monoexponential fashion to determine $K_{\text {mono, }}$ which corresponds to oxidative metabolism [10]. For each individual PET data set, average, septal and lateral wall $K_{\text {mono }}$ values were determined. Average $K_{\text {mono }}$ was derived from the weighted mean of all segmental $K_{\text {mono }}$ values, whereas regionally corresponding segments were combined to generate septal and lateral wall $K_{\text {mono }}$. To derive $\mathrm{MVO}_{2}$ from average $K_{\text {mono, }}$ a relationship between $K_{\text {mono }}$ and myocardial oxygen metabolism $\left(\mathrm{ml} \cdot \mathrm{min}^{-1} \cdot \mathrm{g}^{-1}\right)$, previously established in humans, was used, where $\mathrm{K}_{\text {mono }}=0.0027\left(\mathrm{MVO}_{2}+0.0197\right)$ [19]. Since $\mathrm{MVO}_{2}$ expresses the oxygen consumption per minute, $\mathrm{MVO}_{2}$ per beat was also determined $\left(\mathrm{MVO}_{2 \text { (beat) }}=\mathrm{MVO}_{2} / \mathrm{HR}\right)$.

\section{CMR}

LV volume analysis was performed by manually drawing epicardial and endocardial contours on all ED and ES LV 
short-axis images. Global LV function parameters, including ED volume (LVEDV), ES volume (LVESV), ejection fraction (LVEF) and myocardial mass, were then derived from the cine images with use of the MASS software package (Medis, Leiden, The Netherlands). For LA diameter analysis, epicardial contours were drawn on all LA data sets in ES. The forward SV was obtained from the velocity-encoded phase-contrast aortic flow maps by dividing the forward cardiac output by heart rate (HR).

The tagging images were used to generate circumferential strain curves for each myocardial segment. Subsequently, circumferential shortening $\left(\mathrm{E}_{\mathrm{cc}}\right)$, which reflects maximum myocardial contraction, was derived for each segment from the strain curves [17]. Since circumferential shortening is determined by the shortening of myofibres, $E_{c c}$ is expressed as a negative value. Similar average, septal and lateral wall segmentation was used as described for the PET data.

Finally, each myocardial segment was evaluated for the presence of hyperenhancement, which was defined as an area of signal enhancement greater than $5 \mathrm{SD}$ of the signal of nonenhanced myocardium. The extent of DCE was expressed as the percentage of the total myocardial tissue area studied.

\section{Calculation of myocardial efficiency}

As illustrated by Fig. 2, total mechanical energy is represented by the area between the end-systolic pressurevolume relationship (ESPVR), the end-diastolic pressurevolume relationship (EDPVR) and the pressure-volume loop of the cardiac cycle. The pressure-volume area (PVA) was defined as the sum of external work (EW) and potential energy (PE). EW was determined according to the factor of mean arterial pressure (MAP) and forward stroke volume (SV). In the HCM group, individually obtained estimations of the LVOTG were added to the MAP to ensure accurate

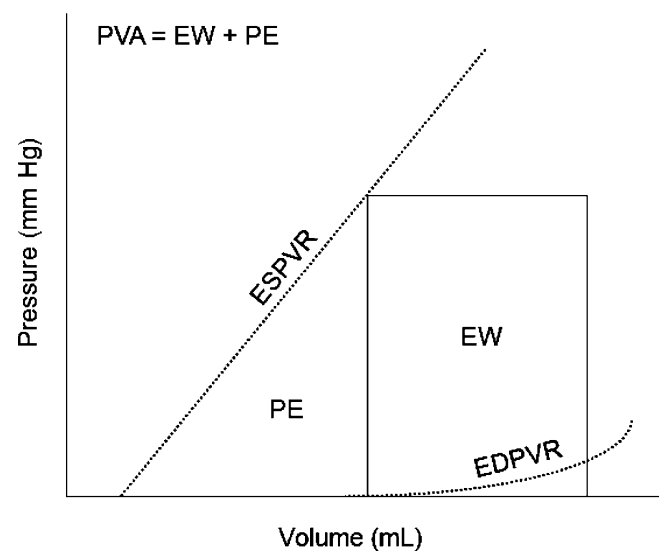

Fig. 2 Schematic representation of a pressure-volume area $(P V A)$. $E W$ external work, $P E$ potential energy, ESPVR end-systolic pressure-volume relationship, EDPVR end-diastolic pressurevolume relationship estimations of actual LV pressures in the case of outflow tract obstruction. Since the end-diastolic pressure-volume point was not available, it was set to zero. The slope of the ESPVR, $E_{\text {es(sb) }}$ expressed in $\mathrm{mmHg} \mathrm{ml} \mathrm{m}^{-1}$, was estimated by use of a previously validated single-beat method [20]. Subsequently, the $x$-axis intercept of the ESPVR was calculated from which point PE and, thus, PVA could be calculated. When the $\mathrm{x}$-axis intercept was negative, it was set to zero. The caloric equivalent of $1 \mathrm{mmHg} \cdot \mathrm{ml}$ equals $1.33 \cdot 10^{-4} \mathrm{~J}$, whereas $1 \mathrm{ml}$ of $\mathrm{O}_{2}$ is $\approx 20 \mathrm{~J}$. Subsequently, mechanical external efficiency (MEE) was calculated according to the equation below [10].

$$
\mathrm{MEE}=\frac{\mathrm{EW} \cdot \mathrm{HR} \cdot 1.33 \cdot 10^{-4}}{\mathrm{MVO}_{2} \cdot \mathrm{LVM} \cdot 20}
$$

Mechanical efficiency (ME) was similarly calculated by substituting EW for PVA area. In addition, the ratio between EW and PVA served as an index for mechanical conversion efficiency. Regional efficiency was determined as the ratio between regional $\mathrm{E}_{\mathrm{cc}}$ and the corresponding $\mathrm{MVO}_{2 \text { (beat), }}$, where more negative values indicate increased efficiency.

\section{Statistics}

Results are displayed as mean \pm SD. Differences between the patients with HCM and controls were assessed by the unpaired Student's $t$ test. The significance of intraindividual differences between the septum and lateral wall were determined with the paired Student's $t$ test. Correlations between variables were evaluated with linear equation analysis. Univariate and multivariate analyses were employed to determine independent predictors of MEE. In the multivariate analyses, stepwise manual backward selection was applied with a removing probability for each variable of $\geq 0.1$. All tests were two-sided and $p$ values $<$ 0.05 were considered statistically significant. Analyses were performed using SPSS 15.0 (Chicago, IL, USA).

\section{Results}

Baseline characteristics of both study groups are shown in Table 1. LV mass (LVM), left atrial size (LA size), NTproBNP, serum FFA and DCE were all significantly increased in the HCM group. SAM was present in 12 HCM patients, whereas a total of 16 patients exhibited a certain degree of MR (grade 1, $n=5$; grade 2, $n=9$; grade 3, $n=2$; grade $4, n=0)$. No significant difference between groups was found for sex, age, body surface area (BSA), $\mathrm{SV}, \mathrm{LV}$ ejection fraction (LVEF), $\mathrm{Hb}$, and serum lactate and glucose levels. 
Table 1 Study population characteristics

\begin{tabular}{llll}
\hline & HCM $(n=20)$ & Controls $(n=11)$ & $p$ \\
\hline Sex & 12 men & 7 men & 0.85 \\
Age (years) & $55 \pm 14$ & $48 \pm 10$ & 0.15 \\
BSA $\left(\mathrm{m}^{2}\right)$ & $2.1 \pm 0.2$ & $2.0 \pm 0.2$ & 0.72 \\
LVM $(\mathrm{g})$ & $200 \pm 76$ & $99 \pm 21$ & 0.001 \\
SV $(\mathrm{ml})$ & $87 \pm 24$ & $102 \pm 26$ & 0.12 \\
LVEF $(\%)$ & $61 \pm 7$ & $61 \pm 5$ & 0.98 \\
LA size $(\mathrm{mm})$ & $144 \pm 41$ & $101 \pm 21$ & 0.003 \\
NT-proBNP $\left(\mathrm{ng} \cdot 1^{-1}\right)$ & $619 \pm 638$ & $61 \pm 53$ & 0.001 \\
Hb (mmol·1 $\left.1^{-1}\right)$ & $8.5 \pm 0.4$ & $8.3 \pm 0.5$ & 0.34 \\
FFA $\left(\mathrm{mmol} \cdot 1^{-1}\right)$ & $0.70 \pm 0.20$ & $0.52 \pm 0.23$ & 0.041 \\
Glucose $\left(\mathrm{mmol} \cdot 1^{-1}\right)$ & $5.2 \pm 1.3$ & $5.6 \pm 0.7$ & 0.29 \\
Lactate $\left(\mathrm{mmol} \cdot 1^{-1}\right)$ & $1.10 \pm 0.61$ & $1.46 \pm 0.65$ & 0.15 \\
DCE $(\%)$ & $4.1 \pm 2.4$ & 0 & $<0.001$ \\
\hline
\end{tabular}

$B S A$ body surface area, $L V M$ left ventricular mass, $S V$ stroke volume, $L V E F$ left ventricular ejection fraction, $S A M$ systolic anterior motion of the mitral valve, LA size maximal left atrial size, NT-proBNP $\mathrm{NH}_{2-}$ terminal pro-brain natriuretic peptide, $H b$ haemoglobin, $F F A$ free fatty acids, $D C E$ delayed contrast enhancement

\section{Haemodynamics}

Haemodynamic parameters obtained during PET for the $\mathrm{HCM}$ and control groups are presented in Table 2. LV outflow tract obstruction (peak LVOTG $>30 \mathrm{mmHg}$ ) was present in $13 \mathrm{HCM}$ patients. The LV outflow tract gradient as well as mean LV pressures were significantly higher in HCM patients (both $p<0.001$ ), whereas arterial blood pressures and heart rates were comparable.
Myocardial metabolism and contractile parameters

PET-derived estimates of $\mathrm{MVO}_{2}$ and MRI-obtained contractile parameters are also depicted in Table 2. $\mathrm{MVO}_{2}$ was comparable between groups $(p=0.64)$, as well as $\mathrm{E}_{\mathrm{es}(\mathrm{sb})}(p=$ 0.30 ). In addition, no significant differences were found between groups for EW $(p=0.83), \operatorname{PE}(p=0.17)$ and PVA $(p=0.54)$.

\section{Myocardial efficiency}

Table 3 lists the estimated efficiency values of HCM patients and controls. MEE was significantly decreased in the HCM group as compared to the control group $(p<0.001)$, as well as $\mathrm{ME}(p<0.001)$. In contrast, mechanical conversion efficiency did not differ between groups $(p=0.80)$.

\section{Determinants of MEE}

The results of univariate and multivariate regression analyses of MEE are depicted in Table 4. MEE was significantly and positively correlated to SV, whereas an inverse correlation was observed with LVOTG, NT-proBNP levels and FFA. When multivariate analysis was performed, SV and LVM remained independent predictors of MEE, and these two factors could predict $83 \%$ of MEE values.

\section{Regional myocardial metabolism and efficiency}

Figure 3a represents $\mathrm{MVO}_{2}$ values for the septum and lateral wall in HCM patients and control subjects. In the HCM group, septal $\mathrm{MVO}_{2 \text { (beat) }}$ was significantly lower compared to

Table 2 Haemodynamics, myocardial oxygen metabolism and contractile parameters

\begin{tabular}{|c|c|c|c|}
\hline & $\mathrm{HCM}$ & Controls & $p$ \\
\hline \multicolumn{4}{|l|}{ Haemodynamics } \\
\hline Systolic BP (mmHg) & $128 \pm 21$ & $122 \pm 12$ & 0.48 \\
\hline Diastolic BP (mmHg) & $70 \pm 8$ & $73 \pm 9$ & 0.46 \\
\hline LVOTG (mmHg) & $22 \pm 11$ & 0 & $<0.001$ \\
\hline LVMAP (mmHg) & $113 \pm 23$ & $89 \pm 9$ & $<0.001$ \\
\hline Heart rate (bpm) & $63 \pm 10$ & $67 \pm 11$ & 0.31 \\
\hline \multicolumn{4}{|l|}{ Oxygen metabolism } \\
\hline $\mathrm{MVO}_{2}\left(\mathrm{ml} \cdot \mathrm{min}^{-1} \cdot \mathrm{g}^{-1}\right)$ & $0.13 \pm 0.05$ & $0.12 \pm 0.04$ & 0.64 \\
\hline \multicolumn{4}{|l|}{ Contractile function } \\
\hline $\mathrm{E}_{\mathrm{es}(\mathrm{sb})}\left(\mathrm{mmHg} \cdot \mathrm{ml}^{-1}\right)$ & $1.42 \pm 0.61$ & $1.15 \pm 0.36$ & 0.30 \\
\hline $\mathrm{EW}(\mathrm{mmHg} \cdot \mathrm{ml})$ & $9,368 \pm 2,907$ & $9,139 \pm 2,484$ & 0.83 \\
\hline $\mathrm{PE}(\mathrm{mmHg} \cdot \mathrm{ml})$ & $3,507 \pm 1,216$ & $2,921 \pm 910$ & 0.17 \\
\hline PVA (mmHg·ml) & $12,875 \pm 3,704$ & $12,060 \pm 3,004$ & 0.54 \\
\hline
\end{tabular}

$B P$ blood pressure, $L V O T G$ left ventricular outflow tract gradient, $L V M A P$ left ventricular mean arterial pressure, $M V O_{2}$ myocardial oxygen consumption, $E_{e s(s b)}$ single-beat estimation of $\mathrm{E}_{\mathrm{es}}, E W$ external work, $P E$ potential energy, $P V A$ pressure-volume area 
Table 3 Myocardial efficiency

\begin{tabular}{llll}
\hline & HCM & Controls & $p$ \\
\hline Mechanical external efficiency $\left(\mathrm{EW} / \mathrm{MVO}_{2}\right)$ & $21 \pm 10 \%$ & $35 \pm 8 \%$ & $<0.001$ \\
Mechanical efficiency $\left(\mathrm{PVA} / \mathrm{MVO}_{2}\right)$ & $30 \pm 14 \%$ & $51 \pm 12 \%$ & $<0.001$ \\
Mechanical conversion efficiency (EW/PVA) & $70 \pm 6 \%$ & $70 \pm 7 \%$ & 0.80 \\
\hline
\end{tabular}

$E W$ external work, $P V A$ pressure-volume area, $\mathrm{MVO}_{2}$ myocardial oxygen consumption

the lateral wall $\left(1.82 \pm 0.63 \cdot 10^{-3} \mathrm{ml} \cdot\right.$ beat $^{-1} \cdot \mathrm{g}^{-1}$ and $1.91 \pm$ $0.65 \cdot 10^{-3} \mathrm{ml} \cdot$ beat $^{-1} \cdot \mathrm{g}^{-1}$ respectively, $\left.p=0.006\right)$. In contrast, septal $\mathrm{MVO}_{2 \text { (beat) }}$ in the control group was comparable to the lateral wall $\left(1.95 \pm 0.55 \cdot 10^{-3} \mathrm{ml} \cdot\right.$ beat $^{-1} \cdot \mathrm{g}^{-1}$ and $1.89 \pm 0.57 \cdot$ $10^{-3} \mathrm{ml} \cdot$ beat $^{-1} \cdot \mathrm{g}^{-1}$ respectively, $\left.p=0.69\right)$. Regional $\mathrm{E}_{\mathrm{cc}}$ values for the septum and lateral wall in the HCM and control groups are depicted in Fig. 3b. In the HCM group, septal $\mathrm{E}_{\mathrm{cc}}$ averaged $-13.0 \pm 2.5 \%$ and was significantly lower compared to the lateral wall $(-15.8 \pm 1.9 \%, p<$ $0.001)$, whereas in the control group $\mathrm{E}_{\mathrm{cc}}$ did not display regional differences (septum: $-17.7 \pm 1.8 \%$, lateral wall: $-18.6 \pm 2.6 \%, p=0.22)$. Consequently, regional efficiency of septum averaged $-7,740 \pm 2,927$ and was significantly lower compared to the lateral wall in the HCM group $(-8,917 \pm 3,767, p=0.006)$. In contrast, regional efficiency in the control group was comparable between the septum and lateral wall $(-10,187 \pm 3,507$ and $-10,924 \pm 4,401$, respectively, $p=0.21$ ) as illustrated by Fig. 3c. Between groups, regional efficiency of the septum was significantly decreased in the HCM group $(p=0.05)$, whereas the lateral wall was comparable $(p=0.20)$.

\section{Discussion}

Myocardial oxygen consumption

The present study demonstrates that $\mathrm{MVO}_{2}$ in $\mathrm{HCM}$ patients is comparable to controls, in line with invasive investigations [21-23]. Similarly, previous non-invasive $\left[{ }^{11} \mathrm{C}\right]$ acetate PET studies in HCM have demonstrated $\mathrm{MVO}_{2}$ in $\mathrm{HCM}$ to be comparable to controls [24] or slightly decreased [2, 25].

\section{Contractile parameters}

LV EW and PVA were also comparable between HCM and controls. However, when corrected for LVM, EW and PVA generated per gram of myocardium were significantly decreased in HCM, in line with other invasive [22] and non-invasive studies [2, 24]. Although not reaching statistical significant, a trend towards an increased slope of the ESPVR was observed in the HCM group, consistent with an invasive study [26].

Table 4 Univariate and multivariate regression analysis of determinants of MEE in patients with HCM

\begin{tabular}{|c|c|c|c|c|c|}
\hline & Univariate & Multivariate & & & \\
\hline & $r$ & $p$ & $y$ & $\beta$ & $p$ \\
\hline BSA & 0.31 & 0.19 & & & \\
\hline LA size & -0.32 & 0.18 & & & \\
\hline LVM & -0.39 & 0.09 & $-0.052(\mathrm{x})+31.43$ & -0.425 & $0.013^{\mathrm{a}}$ \\
\hline SV & 0.58 & $0.008^{\mathrm{a}}$ & $0.247(x)-0.54$ & 0.735 & $<0.001^{\mathrm{a}}$ \\
\hline LVEF & 0.05 & 0.82 & & & \\
\hline NT-proBNP & -0.45 & $0.05^{\mathrm{a}}$ & $-0.009(x)+26.02$ & & \\
\hline FFA & -0.52 & $0.03^{\mathrm{a}}$ & $-24.91(\mathrm{x})+37.14$ & & \\
\hline LVOTG & -0.54 & $0.02^{\mathrm{a}}$ & $-0.453(\mathrm{x})+29.90$ & & \\
\hline HR & -0.42 & 0.06 & & & \\
\hline $\mathrm{E}_{\mathrm{cc}(\mathrm{av})}$ & -0.16 & 0.52 & & & \\
\hline $\mathrm{E}_{\mathrm{es}(\mathrm{sb})}$ & -0.06 & 0.82 & & & \\
\hline DCE & 0.23 & 0.42 & & & \\
\hline
\end{tabular}

$B S A$ body surface area, $L A$ size maximal left atrial size, $L V M$ left ventricular mass, $S V$ forward stroke volume, $L V E F$ left ventricular ejection fraction, $N T$-proBNP $\mathrm{NH}_{2}$-terminal pro-brain natriuretic peptide, FFA free fatty acids, LVOTG left ventricular outflow tract gradient, $H R$ heart rate, $E_{c c}$ maximal circumferential contraction, $E_{e s(s b)}$ single-beat estimation of $\mathrm{E}_{\mathrm{es}}, D C E$ delayed contrast enhancement

${ }^{\text {a }}$ Statistically significant 

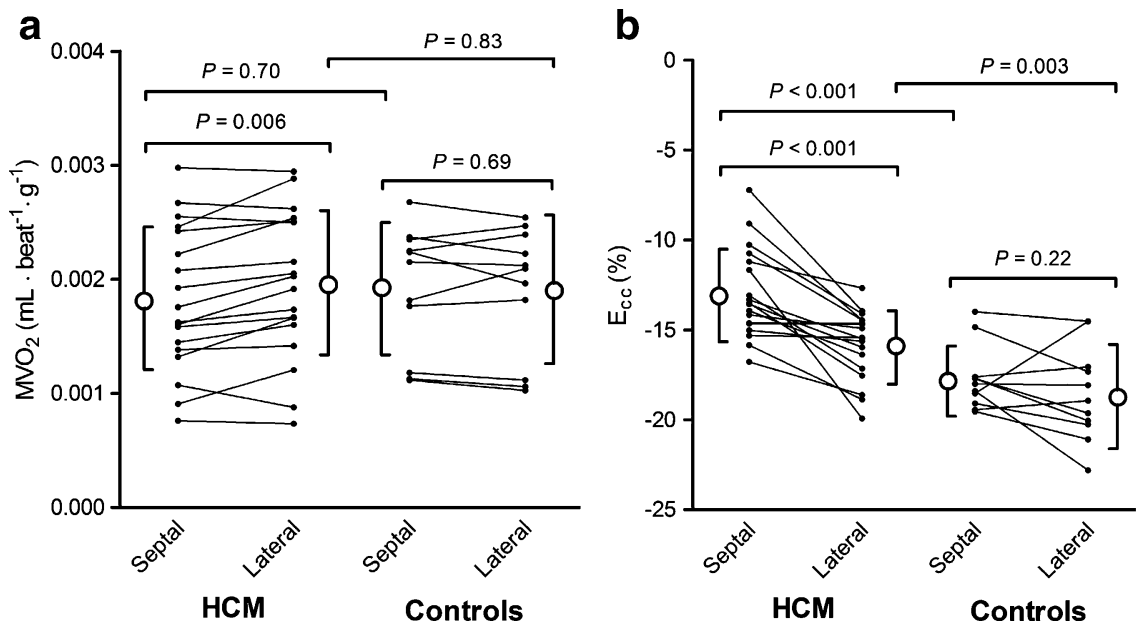

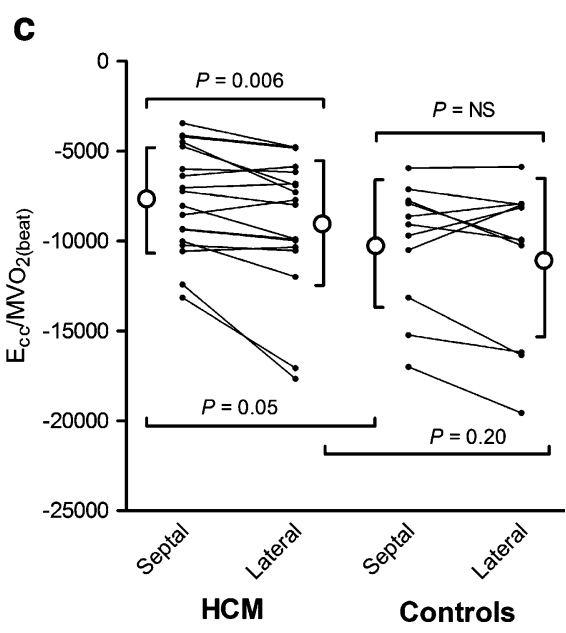

Fig. 3 a Regional $\mathrm{MVO}_{2}$ of the septum and lateral free wall in the control and HCM groups. b Regional $\mathrm{E}_{\mathrm{cc}}$ of the septum and lateral free wall in the control and HCM groups. $\mathbf{c}$ Regional efficiency of the

\section{Myocardial efficiency}

In our series, EW and PVA are disproportionally decreased in relation to oxygen usage in HCM, and therefore occur at the expense of myocardial efficiency. Correspondingly, an early invasive study by Thompson and co-workers in 13 patients with obstructive HCM revealed an MEE of $21 \%$ [22]. Patients with LVH due to hypertension show similar pseudonormalization of $\mathrm{MVO}_{2}$, accompanied by decreased EW generation per gram of myocardium [27], suggesting that mechanoenergetic uncoupling is a distinctive feature in pathological hypertrophy $[8,10]$.

Whether impaired energetics in HCM is the consequence, or the cause, of LVH remains unclear. Nonetheless, impaired energy metabolism in HCM exists even in the absence of hypertrophy, suggesting that compromised energetics precede hypertrophy and may play a causal role in the development of the HCM phenotype [28]. Concordantly, HCM cardiomyocytes exhibit sarcomeric mutations resulting in inefficient ATP utilization, with subsequent increased cost of force generation and excess demand on myocytes [29].

The presence of microvascular dysfunction, a prominent feature of HCM hearts [30], could also have a detrimental impact on myocardial energetics. Microvascular dysfunction results in a blunted perfusion reserve [31, 32] and subsequent myocardial ischaemia during stress [33], even in the non-hypertrophied LV free wall [32]. Therefore, in analogy to ischaemic heart disease due to CAD, repetitive stunning of the myocardium in HCM might contribute to deteriorating efficiency. Clearly, future studies are warranted to investigate the interrelationships between microvascular dysfunction and energetics in HCM.

In contrast to the above, mechanical conversion efficiency remained unaltered between groups and was fairly consistent septum and lateral free wall in the control and HCM groups. $\mathrm{MVO}_{2}$ myocardial oxygen consumption, HCM hypertrophic cardiomyopathy

with investigations in healthy adults $[34,35]$. This indicates that, despite impaired PVA due to inefficient energetics, the transferral ratio from energy production to effective work is preserved.

\section{Regional efficiency}

HCM hearts exhibit marked heterogeneity in regional contractile properties [36-38]. Correspondingly, we have shown that septal $E_{c c}$ was significantly decreased as compared to the lateral wall in the HCM group. Hence, patients with HCM exhibited marked heterogeneity in regional efficiency, especially due to deteriorated energetics of the hypertrophied septum, whereas no significant differences in regional efficiency were observed in the control group. Interestingly, regional efficiency of the lateral wall tended to be lower in HCM patients, when compared to controls, also suggesting global impairment of energetics in HCM patients. Ishiwata et al. have produced similar results indicating a decreased work production to oxygen expenditure ratio in the septum, compared to the lateral wall in HCM [2]. A potential explanation for these regional differences could be the characteristic presence of myofibre disarray in HCM, which can predominantly be found in the interventricular septum located at the insertions with the right ventricle. These oppositely contracting myocytes do not result in an effective contraction pattern and therefore may contribute to reduced MEE [39].

\section{Determinants of MEE}

Deteriorated MEE could independently be correlated to smaller SV and increased LVM. Since SV and LVM are, 
among other cardiac parameters, used to calculate MEE, these results are not startling. Nevertheless, these factors appear to be stronger determinants of MEE than LVOTG, HR, BP or global strain, consequently suggesting a larger potential for therapeutic interventions regarding preservation of SV and/or regression of LVM [24]. In addition, increased haemodynamic pre- and afterload conditions, reflected by increased NT-proBNP levels and outflow tract obstruction, are also important factors related to MEE. Surgical myectomy or alcohol ablation of the hypertrophied septum in HCM reduces LVM by relief of LV outflow obstruction, thereby decreasing extravascular compression forces and inducing chamber remodelling [38, 41-43]. Therefore, regression of afterload-dependent LVH after such a procedure may result in more favourable myocardial energetics, possibly augmenting LV function and improving prognosis in HCM patients.

Finally, where the extent of DCE has previously been shown to be of independent predictive value to impaired efficiency in patients with HCM [40], this could not be reproduced in the present study.

\section{Substrate metabolism}

Next to higher FFA serum concentrations in HCM, we also observed a significant inverse relationship between FFA and MEE in these patients. These increased serum levels of FFA may be related to an augmented sympathetic drive, a well-documented phenomenon in cardiomyopathy and heart failure. This change in metabolic milieu may induce a metabolic switch from myocardial glucose to FFA oxidation [24]. As glucose metabolism yields $11-13 \%$ more ATP per unit of oxygen consumption compared with FFA metabolism, this potential metabolic switch affects mechanical efficiency and could explain the observed correlation between MEE and serum FFA levels in the present study [10]. On the other hand, Tadamura and coworkers observed a switch from FFA to the more efficient glucose oxidation in the presence of hypertrophy [25]. Although it is clear that substrate metabolism in HCM is subject to changes and affects efficiency, future investigations in carefully selected study groups are warranted to further demarcate this issue.

\section{Study limitations}

In the present study we used a previously obtained relationship, obtained in healthy humans, to extrapolate $\mathrm{MVO}_{2}$ from regional $\left[{ }^{11} \mathrm{C}\right]$ acetate clearance rates. It is however unknown whether this relationship is valid in HCM patients, since $K_{\text {mono }}$ is dependent on arterial input, extraction and washout of tracer as well as altered haemodynamic and metabolic conditions of the myocardium.
Furthermore, with regard to the number of variables included in the multivariate analysis, the cohort of HCM patients was relatively small, as a result of which the output should be interpreted with certain care. In addition, the sustained use of medication could affect estimations of actual myocardial efficiency [10], although it should be noted that the currently studied cohort reflects the clinical HCM population.

Finally, non-invasive estimation of work and contractile function is hindered by some important factors. The presence of valvular disease, such as MR in the HCM group, could lead to overestimation of $\mathrm{SV}$, and thus efficiency, because part of the LV volume is ejected in the low-pressured left atrium during systole. We largely circumvented the latter issue by using forward SV only, acquired by MRI flow measurements in the aortic root. In addition, EW is represented as a rectangle in the present study (Fig. 2), not taking into account the area under the EDPVR curve. This results in overestimation of EW and consequently MEE values, especially in patients with decreased LV diastolic elastance (i.e. HCM patients). A range of $\mathrm{PV}$ loops under different loading conditions (e.g. by vena cava inferior occlusion) is warranted to accurately determine the EDPVR and the ESPVR. However, with a recently proposed single-beat method, $\mathrm{E}_{\mathrm{es}(\mathrm{sb})}$ could be obtained non-invasively. The LV end-systolic elastance ensues a parabolic shape, and therefore a little under- or overestimation of $\mathrm{E}_{\mathrm{es}}$ cannot be ruled out.

\section{Conclusion}

Symptomatic HCM is characterized by unaltered $\mathrm{MVO}_{2}$, impaired EW generation per gram of myocardial tissue and subsequent deteriorated myocardial efficiency. MEE could independently be predicted by SV and LVM.

\section{References}

1. Maron BJ. Hypertrophic cardiomyopathy: a systematic review. JAMA 2002;287(10):1308-20.

2. Ishiwata S, Maruno H, Senda M, Toyama H, Nishiyama S, Seki A. Myocardial blood flow and metabolism in patients with hypertrophic cardiomyopathy - a study with carbon-11 acetate and positron emission tomography. Jpn Circ J 1997;61(3):201-10.

3. de Roos A, Doornbos J, Luyten PR, Oosterwaal LJ, van der Wall EE, den Hollander JA. Cardiac metabolism in patients with dilated and hypertrophic cardiomyopathy: assessment with protondecoupled P-31 MR spectroscopy. J Magn Reson Imaging 1992;2(6):711-9.

4. Jung WI, Sieverding L, Breuer J, Hoess T, Widmaier S, Schmidt O, et al. 31P NMR spectroscopy detects metabolic abnormalities in asymptomatic patients with hypertrophic cardiomyopathy. Circulation 1998;97(25):2536-42.

5. Sakuma H, Takeda K, Tagami T, Nakagawa T, Okamoto $S$, Konishi $\mathrm{T}$, et al. 31P MR spectroscopy in hypertrophic cardio- 
myopathy: comparison with Tl-201 myocardial perfusion imaging. Am Heart J 1993;125(5 Pt 1):1323-8.

6. Sieverding L, Jung WI, Breuer J, Widmaier S, Staubert A, van Erckelens F, et al. Proton-decoupled myocardial 31P NMR spectroscopy reveals decreased $\mathrm{PCr} / \mathrm{Pi}$ in patients with severe hypertrophic cardiomyopathy. Am J Cardiol 1997;80(3A):34A40A.

7. Kim IS, Izawa H, Sobue T, Ishihara H, Somura F, Nishizawa T, et al. Prognostic value of mechanical efficiency in ambulatory patients with idiopathic dilated cardiomyopathy in sinus rhythm. J Am Coll Cardiol 2002;39(8):1264-8.

8. Neubauer S. The failing heart-an engine out of fuel. N Engl J Med 2007;356(11):1140-51.

9. Klein LJ, Visser FC, Knaapen P, Peters JH, Teule GJ, Visser CA, et al. Carbon-11 acetate as a tracer of myocardial oxygen consumption. Eur J Nucl Med 2001;28(5):651-68.

10. Knaapen P, Germans T, Knuuti J, Paulus WJ, Dijkmans PA, Allaart CP, et al. Myocardial energetics and efficiency: current status of the noninvasive approach. Circulation 2007;115(7):91827.

11. Götte MJ, Germans T, Rüssel IK, Zwanenburg JJ, Marcus JT, van Rossum AC, et al. Myocardial strain and torsion quantified by cardiovascular magnetic resonance tissue tagging: studies in normal and impaired left ventricular function. J Am Coll Cardiol 2006;48(10):2002-11.

12. Zwanenburg JJ, Götte MJ, Marcus JT, Kuijer JP, Knaapen P, Heethaar RM, et al. Propagation of onset and peak time of myocardial shortening in time of myocardial shortening in ischemic versus nonischemic cardiomyopathy: assessment by magnetic resonance imaging myocardial tagging. J Am Coll Cardiol 2005;46(12):2215-22.

13. Moon JC, McKenna WJ, McCrohon JA, Elliott PM, Smith GC, Pennell DJ. Toward clinical risk assessment in hypertrophic cardiomyopathy with gadolinium cardiovascular magnetic resonance. J Am Coll Cardiol 2003;41(9):1561-7.

14. Knaapen P, Germans T, Camici PG, Rimoldi OE, ten Cate FJ, ten Berg JM, et al. Determinants of coronary microvascular dysfunction in symptomatic hypertrophic cardiomyopathy. Am J Physiol Heart Circ Physiol 2008;294(2):H986-93.

15. Germans T, Götte MJ, Nijveldt R, Spreeuwenberg MD, Beek AM, Bronzwaer JG, et al. Effects of aging on left atrioventricular coupling and left ventricular filling assessed using cardiac magnetic resonance imaging in healthy subjects. Am J Cardiol 2007;100(1):122-7.

16. Marcus JT, Götte MJ, DeWaal LK, Stam MR, Van der Geest RJ, Heethaar RM, et al. The influence of through-plane motion on left ventricular volumes measured by magnetic resonance imaging: implications for image acquisition and analysis. J Cardiovasc Magn Reson 1999;1(1):1-6.

17. Knaapen P, Götte MJ, Paulus WJ, Zwanenburg JJ, Dijkmans PA, Boellaard R, et al. Does myocardial fibrosis hinder contractile function and perfusion in idiopathic dilated cardiomyopathy? PET and MR imaging study. Radiology 2006;240 (2):380-8

18. Knaapen P, Boellaard R, Götte MJ, Dijkmans PA, van Campen LM, de Cock CC, et al. Perfusable tissue index as a potential marker of fibrosis in patients with idiopathic dilated cardiomyopathy. J Nucl Med 2004;45(8):1299-304.

19. Sun KT, Yeatman LA, Buxton DB, Chen K, Johnson JA, Huang $\mathrm{SC}$, et al. Simultaneous measurement of myocardial oxygen consumption and blood flow using [1-carbon-11] acetate. J Nucl Med 1998;39(2):272-80

20. Chen CH, Fetics B, Nevo E, Rochitte CE, Chiou KR, Ding PA, et al. Noninvasive single-beat determination of left ventricular endsystolic elastance in humans. J Am Coll Cardiol 2001;38 (7):2028-34.
21. Cannon 3rd RO, Rosing DR, Maron BJ, Leon MB, Bonow RO, Watson RM, et al. Myocardial ischemia in patients with hypertrophic cardiomyopathy: contribution of inadequate vasodilator reserve and elevated left ventricular filling pressures. Circulation 1985;71(2):234-43.

22. Thompson DS, Naqvi N, Juul SM, Swanton RH, Coltart DJ, Jenkins BS, et al. Effects of propranolol on myocardial oxygen consumption, substrate extraction, and haemodynamics in hypertrophic obstructive cardiomyopathy. Br Heart J 1980;44(5):488-98.

23. Cannon 3rd RO, McIntosh CL, Schenke WH, Maron BJ, Bonow RO, Epstein SE. Effect of surgical reduction of left ventricular outflow obstruction on hemodynamics, coronary flow, and myocardial metabolism in hypertrophic cardiomyopathy. Circulation 1989;79(4):766-75.

24. Tuunanen H, Kuusisto J, Toikka J, Jääskeläinen $P$, Marjamäki $P$, Peuhkurinen K, et al. Myocardial perfusion, oxidative metabolism, and free fatty acid uptake in patients with hypertrophic cardiomyopathy attributable to the Asp175Asn mutation in the alpha-tropomyosin gene: a positron emission tomography study. J Nucl Cardiol 2007;14(3):354-65.

25. Tadamura E, Tamaki N, Matsumori A, Magata Y, Yonekura Y, Nohara R, et al. Myocardial metabolic changes in hypertrophic cardiomyopathy. J Nucl Med 1996;37(4):572-7.

26. Meliga E, Steendijk P, Valgimigli M, Ten Cate FJ, Serruys PW. Effects of percutaneous transluminal septal myocardial ablation for obstructive hypertrophic cardiomyopathy on systolic and diastolic left ventricular function assessed by pressure-volume loops. Am J Cardiol 2008;101(8):1179-84.

27. Laine H, Katoh C, Luotolahti M, Yki-Järvinen H, Kantola I, Jula A, et al. Myocardial oxygen consumption is unchanged but efficiency is reduced in patients with essential hypertension and left ventricular hypertrophy. Circulation 1999;100 (24):2425-30.

28. Crilley JG, Boehm EA, Blair E, Rajagopalan B, Blamire AM, Styles $\mathrm{P}$, et al. Hypertrophic cardiomyopathy due to sarcomeric gene mutations is characterized by impaired energy metabolism irrespective of the degree of hypertrophy. J Am Coll Cardiol 2003;41(10): 1776-82.

29. Redwood CS, Moolman-Smook JC, Watkins H. Properties of mutant contractile proteins that cause hypertrophic cardiomyopathy. Cardiovasc Res 1999;44(1):20-36.

30. Camici PG, Crea F. Coronary microvascular dysfunction. N Engl J Med 2007;356(8):830-40.

31. Krams R, Kofflard MJ, Duncker DJ, Von Birgelen C, Carlier S, Kliffen $\mathrm{M}$, et al. Decreased coronary flow reserve in hypertrophic cardiomyopathy is related to remodeling of the coronary microcirculation. Circulation 1998;97(3):230-3.

32. Camici PG, Chiriatti G, Lorenzoni R, Bellina RC, Gistri R, Italiani $G$, et al. Coronary vasodilation is impaired in both hypertrophied and nonhypertrophied myocardium of patients with hypertrophic cardiomyopathy: a study with nitrogen-13 ammonia and positron emission tomography. J Am Coll Cardiol 1991;17 (4):879-86.

33. Maron MS, Olivotto I, Maron BJ, Prasad SK, Cecchi F, Udelson JE, et al. The case for myocardial ischemia in hypertrophic cardiomyopathy. J Am Coll Cardiol 2009;54(9):866-75.

34. Kameyama T, Asanoi H, Ishizaka S, Yamanishi K, Fujita M, Sasayama S. Energy conversion efficiency in human left ventricle. Circulation 1992;85(3):988-96.

35. Porenta G, Cherry S, Czernin J, Brunken R, Kuhle W, Hashimoto $\mathrm{T}$, et al. Noninvasive determination of myocardial blood flow, oxygen consumption and efficiency in normal humans by carbon11 acetate positron emission tomography imaging. Eur $\mathrm{J}$ Nucl Med 1999;26(11):1465-74.

36. Ennis DB, Epstein FH, Kellman P, Fananapazir L, McVeigh ER, Arai AE. Assessment of regional systolic and diastolic dysfunc- 
tion in familial hypertrophic cardiomyopathy using MR tagging. Magn Reson Med 2003;50(3):638-42.

37. Knaapen P, van Dockum WG, Götte MJ, Broeze KA, Kuijer JP, Zwanenburg JJ, et al. Regional heterogeneity of resting perfusion in hypertrophic cardiomyopathy is related to delayed contrast enhancement but not to systolic function: a PET and MRI study. J Nucl Cardiol 2006;13(5):660-7.

38. van Dockum WG, Kuijer JP, Götte MJ, Ten Cate FJ, Ten Berg JM, Beek AM, et al. Septal ablation in hypertrophic obstructive cardiomyopathy improves systolic myocardial function in the lateral (free) wall: a follow-up study using CMR tissue tagging and 3D strain analysis. Eur Heart J 2006;27(23):2833-9.

39. Tseng WY, Dou J, Reese TG, Wedeen VJ. Imaging myocardial fiber disarray and intramural strain hypokinesis in hypertrophic cardiomyopathy with MRI. J Magn Reson Imaging 2006;23(1):1-8.

40. Esposito A, De Cobelli F, Perseghin G, Pieroni M, Belloni E, Mellone R, et al. Impaired left ventricular energy metabolism in patients with hypertrophic cardiomyopathy is related to the extension of fibrosis at delayed gadolinium-enhanced magnetic resonance imaging. Heart 2009;95(3):228-33.

41. Soliman OI, Geleijnse ML, Michels M, Dijkmans PA, Nemes A, van Dalen BM, et al. Effect of successful alcohol septal ablation on microvascular function in patients with obstructive hypertrophic cardiomyopathy. Am J Cardiol 2008;101(9):13217.

42. Steendijk P, Meliga E, Valgimigli M, Ten Cate FJ, Serruys PW. Acute effects of alcohol septal ablation on systolic and diastolic left ventricular function in patients with hypertrophic obstructive cardiomyopathy. Heart 2008;94(10):131822.

43. Deb SJ, Schaff HV, Dearani JA, Nishimura RA, Ommen SR. Septal myectomy results in regression of left ventricular hypertrophy in patients with hypertrophic obstructive cardiomyopathy. Ann Thorac Surg 2004;78(6):2118-22. 